\title{
DISPUTAS POR POSIÇÃO DE DESTAQUE: SER AUTOR OU SE CONTENTAR COMO MERO COLABORADOR?
}

\author{
Roberta Pessoa Moreira'
}

\section{RESUMO}

O artigo objetiva esclarecer a distinção entre colaboradores e coautores de uma pesquisa mediante estudo bibliográfico e documental. Serão abordados dois casos submetidos ao Committee on Publication Ethics - COPE, nos anos de 2016 e de 2018, acerca de disputas entre autor e colaborador. Compreende-se que o autor é aquele que contribui substancialmente, desde a primeira etapa, até a revisão e publicação de um trabalho, enquanto o colaborador apenas presta auxílios à pesquisa, de modo a ser designado apenas na seção de agradecimentos. $\mathrm{O}$ assunto é importante para garantir a ética e a integridade das pesquisas no meio acadêmico.

Palavras-chave: Direitos Autorais. Autoria. Disputas. Indicador de Colaboração. Ética.

\section{DISPUTES FOR FEATURED POSITION: BE AUTHOR OR CONTENT AS A MERRY COLLABORATOR?}

\begin{abstract}
The paper aims to clarify the distinction between collaborators and co-authors of a research through bibliographic and documentary study. Two cases will be addressed to the Committee on Publication Ethics - COPE, in 2016 and 2018, concerning disputes between author and collaborator. It is understood that the author is the one who contributes substantially, from the first stage, to the review and publication of a work, while the contributor only provides aid to the research, so that it is only designated in the acknowledgments section. The issue is important to ensure the ethics and integrity of research in academia.
\end{abstract}

Keywords: Copyright. Authorship. Disputes. Collaboration Indicator. Ethics.

\section{INTRODUÇÃO}

O sucesso dos pesquisadores no meio acadêmico vem sendo medido por números. Quanto mais se produz, mais prestígio, credibilidade e notoriedade eles ganham. Essa prática faz com que pesquisadores ansiosos por reconhecimento ajam ou se omitam, em algumas situações, de modo antiético, comprometendo a integridade dos trabalhos científicos e gerando disputas acerca da autoria.

\footnotetext{
${ }^{1}$ Mestranda em Direito, Acesso à Justiça e ao Desenvolvimento pela UNICHRISTUS. Especialista em Direito Público pela ESMEC. Bacharela em Direito pela UNIFOR. Analista Judiciária - Área Judiciária na Justiça Federal no Ceará, exercendo a função de assessora. E-mail: pessoa_roberta@hotmail.com.
} 
Destacam-se, neste artigo, os casos de dúvidas envolvendo a delimitação das contribuições em uma pesquisa a fim de que se especifique quem deve ser o real autor do trabalho e quem deve figurar, em seção de agradecimento, como colaborador.

Em que pese existirem diretrizes, como as estabelecidas pelo Comitê de Política Editorial (CSE), pelo Conselho Nacional de Desenvolvimento Científico e Tecnológico (CNPq), pela Fundação de Amparo à Pesquisa do Estado de São Paulo (FAPESP) e pelo Committee on Publication Ethics (COPE), que dispõem, de modo geral, acerca das atribuições que são próprias de autores e das que designam os colaboradores, ocorrem disputas, principalmente de indivíduos que são considerados colaboradores e que entendem que suas contribuições foram suficientes para o merecimento do destaque da autoria.

Nesse contexto, o COPE, fórum de editores de periódicos científicos, costuma receber casos envolvendo disputas, incluindo as que tratam da distinção entre autor e colaborador, e estabelece recomendações de quais as melhores medidas para solucionar as questões conflituosas (COPE, 2019).

Discutem-se, nesta pesquisa, quais os critérios para distinguir meros colaboradores, destinados a figurar em uma seção de agradecimentos, de coautores, que merecem ser prestigiados pela autoria da produção acadêmica, com base no desempenho e dedicação ofertados para o desenvolvimento do trabalho científico.

Acredita-se que, para ser considerado autor, é preciso contribuição substancial, o que inclui materialização de esforço intelectual em todo o desenvolvimento da pesquisa até a formulação dos resultados e posterior revisão de publicação do trabalho.

Considera-se que simples levantamentos de dados, auxílios de financiamento e contribuições de estatísticas e de documentos ensejam apenas o reconhecimento do pesquisador como colaborador em uma seção de agradecimentos.

Pretende-se, assim, sanar dúvidas em torno da real autoria e da simples atuação como colaborador, bem como investigar soluções para diminuir a dificuldade, pelos pesquisadores, na atribuição da autoria, a fim de evitar conflitos nessa temática.

Debater o assunto, em meio acadêmico e com alcance social, é necessário diante da frequência com que estes conflitos, envolvendo delimitação de quem é autor e de quem é colaborador, ocorrem e terminam por ferir a ética e a integridade das pesquisas científicas.

Ademais, as contribuições que serão desenvolvidas nesta pesquisa poderão incentivar que investigações relacionadas a esta temática, mas com outros enfoques, sejam despertadas e 
ajudem a esclarecer as dúvidas em torno da autoria, contribuindo para que os pesquisadores tenham condutas pautadas pela ética e, consequentemente, preocupem-se com a integridade da pesquisa científica.

Do ponto de vista metodológico, será realizado estudo bibliográfico mediante a análise dos conteúdos existentes em revistas, artigos e publicações especializadas na Internet em torno das disputas de autoria e da delimitação das contribuições de autor e de mero colaborador.

Será desenvolvida também pesquisa documental por meio de dados oficiais publicados na Internet e da análise de casos concretos levados ao COPE envolvendo conflitos em torno da distinção de autor e de colaborador.

Entre 02 de junho e 05 de agosto do ano de 2019 foram analisados dezoito casos submetidos ao COPE, encerrados ou ainda em andamento entre os anos de 2016 e de 2019, envolvendo autoria e contribuição. Todavia, serão destacados e comentados dois, um referente ao ano de 2016 e outro ao ano de 2018, que envolvem, especificamente, disputas de autoria entre colaboradores e autores.

O elemento central deste artigo será contribuir na ampliação do conhecimento em relação à distinção de autor e de colaborador no meio acadêmico, motivo pela qual, segundo a utilização dos resultados, a pesquisa classifica-se como pura.

A abordagem será qualitativa, pois consistirá na análise, na observação e na consequente compreensão tanto da bibliografia quanto dos documentos referenciados. Quanto aos objetivos, a pesquisa será descritiva, pois focará na análise e no registro da temática, e exploratória, dada a busca pelo alcance dos objetivos e à averiguação de maiores informações sobre o tema.

O método utilizado será o hipotético-indutivo, uma vez que, a partir da análise dos dois casos selecionados do COPE e da compilação teórica acerca da delimitação das contribuições que distinguem autor de colaborador, haverá a tentativa de obter o resultado central da pesquisa em torno de esclarecer a problemática acerca da real autoria e da simples atuação como colaborador e diminuir a dificuldade, pelos pesquisadores, na atribuição da autoria.

Para tanto, na segunda seção, serão correlacionadas as exigências e pressões sofridas no meio acadêmico pelos pesquisadores com o comprometimento ético e de integridade das pesquisas, cenário em que se destacam as disputas por autoria. Será feita a distinção em 
relação aos autores e aos colaboradores, mediante o apontamento de diretrizes extraídas de instituições de pesquisa e de fontes bibliográficas, que, no intuito de propagar a ética e as boas condutas no meio acadêmico, contribuíram para delimitar esses dois atores.

Na terceira seção, por fim, serão apresentados dois casos levados ao COPE, um no ano de 2016 e outro no ano de 2018, em que foram suscitadas dúvidas em torno da definição de pesquisar como autor ou como mero colaborador. Na oportunidade, serão mostradas as sugestões oferecidas pelo fórum para a solução das controvérsias e serão tecidos comentários dos casos em consonância com as delimitações teóricas dispostas na segunda seção do trabalho.

\section{CRITÉRIOS DE DISTINÇÃO ENTRE AUTOR E MERO COLABORADOR DA PESQUISA CIENTÍFICA}

A preocupação, no meio acadêmico, em corretamente diferenciar o autor do colaborador, decorre de disputas movidas por indivíduos descontentes em não ter seu nome incluído em nenhum ponto do trabalho ou que acreditam que suas contribuições foram relevantes, não justificando figurarem apenas em uma seção de agradecimento.

A ausência de especificação das contribuições de cada pesquisador no trabalho científico, qualificando-os como autor ou meros colaboradores, consiste em má prática acadêmica, uma vez que possibilita que créditos sejam atribuídos ou não, injustamente, sem respeito aos princípios éticos (GARCIA, 2010).

Antes de adentrar nos critérios de diferenciação entre autor e colaborador, faz-se importante mencionar que as disputas de autoria são motivadas, entre outros fatores, pela pressão ocasionada pelo tempo escasso e pela exigência de produção para que o pesquisador seja reconhecido e bem aceito no meio acadêmico, resultando no comprometimento do fluxo das boas ideias, da inovação e de desenvolvimento de pesquisas úteis (BEDÊ; SOUSA, 2018).

A superação de metas, levando em consideração a quantidade de produção científica por autor, é objetivo também de pesquisadores que pretendem obter financiamentos de pesquisas. A cobrança e a pressão por publicação são, então, constantes na rotina dos pesquisadores que pretendem obter êxito no meio acadêmico (DOMINGUES, 2013).

O excesso de produção, sem o devido cuidado e esmero com a qualidade, termina, assim, não apenas por assolar, negativamente, a ciência, do ponto de vista de conteúdos 
redundantes que são difundidos, como também é causa da prática de condutas questionáveis, do ponto de vista ético (BEDÊ; MESQUITA; PUCCI, 2018).

Posturas controversas e antiéticas são assumidas por alguns pesquisadores, ansiosamente preocupados em ocupar posição de liderança, prestígio ou satisfação individual no universo da Academia (VILAÇA, 2015).

Surge, portanto, a necessidade de bem definir as contribuições de cada pesquisador, pois, como explana Garcia (2010), reconhecer a autoria é não só dar relevância ao esforço intelectual do autor em relação ao seu objeto de estudo, mas também honrar a sua reputação, conferindo credibilidade a ele no meio acadêmico. O reconhecimento da autoria é, desse modo, direito moral do autor ${ }^{2}$.

Para a Associação Brasileira de Editores Científicos (2017), o CSE estabelece diretrizes que primam pela integridade em publicações de periódicos científicos. Essas orientam que a autoria é concedida a quem se esforçou, consideravelmente, ao ponto de obter os créditos do trabalho e, de modo sucinto, expõem os princípios comuns para a definição de quem é considerado autor em relação a todas as áreas da Ciência.

As diretrizes do CSE estabelecem que é incumbência dos pesquisadores, e não do editor que será responsável pela publicação, a definição de quem irá figurar como autor e daqueles que serão definidos como mero colaboradores, a ser identificados em uma seção relativa aos agradecimentos. Por ser do autor a responsabilidade pelo resultado final do estudo científico, expõem que é importante, para a ciência dos leitores, a definição das contribuições,

\footnotetext{
${ }^{2}$ A Lei no 9.610 , de 19 de fevereiro de 1998, instrumento normativo que altera, consolida e atualiza a legislação sobre direito autorais, dispõe, em seu Capítulo II, sobre os direitos morais do autor. Destacam-se sobre o assunto, as disposições contidas nos incisos do artigo 24, da mencionada lei:

Art. 24. São direitos morais do autor:

I - o de reivindicar, a qualquer tempo, a autoria da obra;

II - o de ter seu nome, pseudônimo ou sinal convencional indicado ou anunciado, como sendo o do autor, na utilização de sua obra;

III - o de conservar a obra inédita;

IV - o de assegurar a integridade da obra, opondo-se a quaisquer modificações ou à prática de atos que, de qualquer forma, possam prejudicá-la ou atingi-lo, como autor, em sua reputação ou honra;

$\mathrm{V}$ - o de modificar a obra, antes ou depois de utilizada;

VI - o de retirar de circulação a obra ou de suspender qualquer forma de utilização já autorizada, quando a circulação ou utilização implicarem afronta à sua reputação e imagem;

VII - o de ter acesso a exemplar único e raro da obra, quando se encontre legitimamente em poder de outrem, para o fim de, por meio de processo fotográfico ou assemelhado, ou audiovisual, preservar sua memória, de forma que cause o menor inconveniente possível a seu detentor, que, em todo caso, será indenizado de qualquer dano ou prejuízo que the seja causado.
} 
tanto de autores quanto de colaboradores (ASSOCIAÇÃO BRASILEIRA DE EDITORES CIENTÍFICOS, 2017).

Ao definir o autor como quem contribuiu, substancialmente e de modo significativo, no resultado do trabalho e coadunou em ser o responsável por suas contribuições, as diretrizes especificam alguns tipos de colaborações que não permitem a associação à autoria, tais como simples participação na construção do manuscrito, mas sem atuar nas fases que envolvem o estudo e/ou apontamentos dos resultados, bem como “[...] auxiliar na pesquisa fornecendo aconselhamento, espaço para pesquisa, supervisão departamental, apoio financeiro, análises isoladas ou fornecimento de reagentes/pacientes/animais/outros materiais de estudo" (ASSOCIAÇÃO BRASILEIRA DE EDITORES CIENTÍFICOS, 2017, p.33).

Austrian Agency for Scientific Integrity - ÖeAWI (2006 apud Vilaça, 2015) define que a contribuição substancial consiste em, a partir do tema e do plano do trabalho, o pesquisador não só avaliar e interpretar dados e resultados, mas também desenvolver o trabalho e sugerir pontos essenciais para revisão.

Assim, só devem ser considerados autores aqueles que, efetivamente, participam e se responsabilizam por todas as etapas do trabalho, desde o plano das ideias, a designação de objetivos, as escolhas da metodologia a ser utilizada, a interpretação dos resultados alcançados, até a elaboração preliminar e final do texto (TARGINO, 2010).

Desse modo, aqueles que colaboram, mas não fornecem subsídios suficientes para ocupar a autoria do trabalho, devem ser mencionados na seção de agradecimentos, e devem consentir, por meio da aposição de suas assinaturas, com a divulgação de seus nomes, cabendo a eles, antes da publicação do trabalho, manifestar possíveis disputas de interesses. Austrian Agency for Scientific Integrity - ÖeAWI (2006 apud Vilaça, 2015, p. 261) explana que, consoante a ÖeAWI:

[...] a participação de natureza estritamente técnica na coleta de dados, fornecendo apoio financeiro ou simplesmente dirigindo um departamento, laboratório ou afim, no qual a pesquisa é realizada, não constitui uma base válida para a coautoria. O mesmo se aplica à mera revisão de um manuscrito, sem fazer uma contribuição intelectual ao seu conteúdo. A agência afirma ainda que, ao aceitar ser nomeado como coautor, um cientista ou pesquisador assume a responsabilidade conjunta para garantir que a publicação satisfaça às exigências das boas práticas científicas.

A seção relativa aos agradecimentos costuma ser utilizada de forma adequada ao indicar os nomes que patrocinaram o trabalho e o local em que a pesquisa se desenvolveu, 
além de evidenciar a boa índole dos autores por externarem sentimento de gratidão em relação aos pesquisadores que auxiliaram na produção científica (PETROIANU, 2012).

Mas, em alguns casos, é utilizada de maneira imprópria, quando os autores incluem nomes excessivos que tiveram ínfimas contribuições, o que termina por subestimar ou desvalorizar os que mereciam efetivo reconhecimento (PETROIANU, 2002).

É importante ressaltar que fere critérios éticos e implica má conduta apontar, na seção de agradecimento, indivíduos que não se envolveram na pesquisa e em nada contribuíram para o trabalho (WAGER; KLEINERT, 2014).

Dessa maneira, apesar de o autor e de o colaborador acrescentarem na produção, atuarem como contribuidores do trabalho e constituírem, assim, o conceito mais amplo de colaboradores científicos, possuem papéis distintos e, em consequência, recebem tratamento dentro da pesquisa de modo diferenciado. Além disso, a definição acerca de quem assinará um artigo como autor e quem figurará como colaborador em seção de agradecimentos varia de acordo com as áreas científicas e o contexto social no qual estão inseridos os pesquisadores (VANZ; STUMPF, 2010).

Tendo em vista que cada área da ciência tem suas especificidades em relação às contribuições para identificação da autoria e que as diretrizes do CSE tratam-se de princípios em comum a todas as áreas, Wager e Kleinert (2014) compreendem que a melhor maneira de estabelecer com precisão a diferenciação entre autor e colaborador, de acordo com cada área de pesquisa, ocorre por meio das próprias instituições de pesquisa, acadêmicas, profissionais e por financiadores.

Assim, de acordo com Wager e Kleinert (2014), os autores, com base nos critérios fixados por periódicos ou instituições de sua área científica, responsabilizam-se por atribuir corretamente a autoria e designar quem deve figurar como colaborador na seção de agradecimento ou de reconhecimento.

Destaca-se também a colaboração do CNPq para que sejam asseguradas a ética e a integridade nas produções científicas, evitando-se as más condutas de pesquisadores.

O CNPq instituiu a Comissão de Integridade na Atividade Científica (CIAC), que tem como um de seus objetivos gerais verificar casos em que há dúvidas sobre a integridade da pesquisa mediante auxílio de especialistas da área que podem emitir parecer (CNPq, 2019a). 
Para alcançar seus escopos, a CIAC desenvolveu diretrizes, entre as quais, diante da temática abordada neste artigo, merecem destaque as de números 16 e 17, que tratam da distinção entre autores e meros colaboradores (CNPq, 2019b, p. 6):

[...] 16. A inclusão de autores no manuscrito deve ser discutida antes de começar a colaboração e deve se fundamentar em orientações já estabelecidas, tais como as do International Committee of Medical Journal Editors. 17. Somente as pessoas que emprestaram contribuição significativa ao trabalho merecem autoria em um manuscrito. Por contribuição significativa entende-se realização de experimentos, participação na elaboração do planejamento experimental, análise de resultados ou elaboração do corpo do manuscrito. Empréstimo de equipamentos, obtenção de financiamento ou supervisão geral, por si só não justificam a inclusão de novos autores, que devem ser objeto de agradecimento.

Por meio da CIAC e das diretrizes por ela expostas, o CNPq tem a notória intenção de pautar constantemente a ética, associada à consciência moral de cada pessoa em relação a suas ações, na área da pesquisa, contribuindo na tentativa de coibir as más práticas $(\mathrm{CNPq}$, 2019b).

No mesmo sentido, a FAPESP elaborou o Código de Boas Práticas Científicas, mediante o qual, no item 3.2.6, identifica o autor ao pesquisador que contribuiu intelectualmente, de modo direto e com grau de importância, para a realização da pesquisa e dos resultados apresentados, de modo que quem se limita a financiar ou fornecer subsídios estruturais não deve ser identificado como autor (FAPESP, 2014).

Interessante também mencionar que, em um painel envolvendo editores de periódicos e especialistas, na Academia Nacional de Ciências dos Estados Unidos, foram definidas recomendações para garantir a segurança e a transparência na atribuição de autoria (McNUTT, 2018)

A proposta disseminada no painel foi a definição de um plano prático no qual sejam compiladas as políticas e diretrizes de periódicos a fim de eliminar os conflitos que permeiam a atribuição da autoria (McNUTT, 2018).

Segundo McNutt (2018), a novidade, no evento, foi a estratégia de disseminar o Contributor Roles Taxonomy (CrediT), metodologia lançada no ano de 2014 que reconhece quatorze contribuições diferentes de um indivíduo em relação a um artigo, com o propósito de conceder crédito a papéis considerados instrumentais, como coleta de dados, realização de experimentos e obtenção de recursos. 
A consideração feita, no painel, segundo o autor citado anteriormente, foi a de que estas contribuições, geralmente menosprezadas, podem tomar proporções além do artigo para o qual colaboraram e, portanto, merecem reconhecimento. Para isso, em cada artigo, deverão constar dados com descrição de todas as contribuições.

Discutiu-se no painel que deveria ser incentivada, por agências de fomento, a combinação do CrediT ao Open Researcher and Contributor ID (Orcid), que se refere a uma assinatura digital própria do pesquisador a fim de delimitar a sua contribuição, no intuito de recuperar as exatas colaborações de pesquisadores, ainda que não tenham sido considerados autores, em publicações científicas (McNUTT, 2018).

As considerações feitas no painel, conforme McNutt (2018), não se limitaram a metodologias, mas também a sugestões de que as revistas científicas deveriam padronizar, por meio da formalização de uma declaração, as contribuições que ensejam a assinatura de um artigo na condição de autor, bem como que os autores concordem com sua participação, evitando eventuais questões conflituosas.

\section{DISPUTAS CONCRETAS LEVADAS AO COPE ENVOLVENDO AUTOR E COLABORADOR}

No contexto que envolve as disputas de autoria, é relevante mencionar o COPE, fórum estabelecido por editores de jornais científico no qual também se discute sobre a integridade de trabalhos científicos publicados nos periódicos. Ele empenha-se em apoiar, direcionar e educar os editores, assim como todos os envolvidos em uma publicação científica para que as condutas sejam sempre pautadas pela ética (COPE, 2019).

O referido Comitê tem recomendações próprias acerca da identificação de autores e meros colaboradores, na medida em que dispõe que cabe aos autores, no mínimo, assumir parte da responsabilidade do estudo científico, além de ser necessário chegar a um consenso acerca do que se espera de cada colaborador com as devidas distinções em relação à autoria a fim de evitar disputas (COPE, 2003).

Após a análise de dezoito casos, encerrados ou ainda em andamento, entre os anos de 2016 e de junho de 2019, submetidos ao COPE, destacam-se dois que envolvem, especificamente, disputas de autoria entre colaboradores e autores, os quais serão a seguir descritos e analisados com base no arcabouço teórico realizado na seção anterior. 
O primeiro caso destacado do COPE foi referente ao ano de 2016. Submeteu-se a uma revista médica um artigo sobre os efeitos benéficos de um tratamento com uma preparação biológica, realizada em farmácia, bastante onerosa. Entre os autores, constou um funcionário da empresa responsável pela produção e pela venda do fármaco. Outros funcionários foram listados na seção de agradecimento, conforme suas contribuições (COPE, 2016).

No momento da revisão do artigo pelo editor, verificou-se que foram feitas modificações no trabalho por um indivíduo que não estava listado como autor nem como colaborador nos agradecimentos e, por motivo de transparência, convocaram-se os autores. Estes, por sua vez, explanaram que o indivíduo, responsável pelas alterações, substituiu o funcionário da empresa que havia sido mencionado na seção de agradecimentos e, no tempo da substituição, reuniu comentários dos autores e preparou a versão revisada do artigo para submissão, o que, para o editor, seria contribuição substancialmente significativa (COPE, 2016).

O fórum mencionou que não é responsabilidade do editor atribuir a autoria, cabendo essa aos próprios autores em conformidade com a instituição a que se vinculam, razão pela qual essa deveria ser acionada a fim de solucionar a questão. Mencionou também que, como tentativa de esclarecer o caso, poderia ser realizado contato diretamente com o indivíduo e expostas as diretrizes do International Committee of Medical Journals Editors (ICMJE) a fim de que ele autodeclarasse suas contribuições e afirmasse se preenchia os requisitos para a autoria (COPE, 2016).

O fórum fez a avaliação de que as contribuições do indivíduo, ao ajudar os escritores a complementarem e juntarem seus trabalhos, não enriqueceram intelectualmente o artigo, e, assim, mencioná-lo em seção de agradecimentos parecia ser a melhor decisão. Por fim, o fórum tornou pública a resolução do caso em que se decidiu pela inclusão do funcionário da empresa em discussão na seção de agradecimentos e que a editora recebeu e-mail desse concordando em ser assim mencionado (COPE, 2016).

O caso tratou, exatamente, do questionamento acerca de a quem deve ser atribuída a autoria e da tentativa de solução com base na identificação da substancialidade, da importância e da magnitude ou não das colaborações.

Afinal, ser autor significa responsabilizar-se pelo trabalho, diante da presunção de integridade nele contida, assim como estar sempre preparado para sustentar as ideias nele 
existentes. Já o colaborador, pessoa que auxilia no estudo, mas cuja contribuição não tem conformidade com os critérios do ICMJE, deve ser destacado na seção de agradecimento com todas as suas contribuições especificadas e descritas, bem como com a permissão, por escrito, para figurar no agradecimento, a fim de que todas essas observações sejam do conhecimento dos leitores (MONTEIRO, 2004).

Dessa maneira, faz-se necessário, com base na análise das contribuições dos pesquisadores, em cada caso concreto, avaliar a importância de cada colaboração a fim de atribuir o destaque do indivíduo como autor ou sua menção como mero colaborador.

Nesse caso, foi recomendada a procura da instituição por parte de quem suscitou a dúvida para a correta atribuição da autoria e este ponto será retratado na análise do caso a seguir, que também ressaltou essa questão.

O segundo caso foi discutido e encerrado pelo COPE no ano de 2018. Tratou de uma dúvida levantada por um periódico ao fórum sobre a quem atribuir a autoria de um artigo diante de um conflito que surgiu após a publicação, em que o pesquisador A afirmou que era o autor legítimo, uma vez que continha dados sobre o paciente, objeto de estudo, pois recebeu o material colhido em cirurgia e concedeu o diagnóstico do enfermo (COPE, 2018).

O pesquisador A mencionou também que deu autorização ao pesquisador B para que apresentasse o caso em uma conferência, mas este foi além, na medida em que, tempos depois, publicou um artigo no periódico questionador e sem a sua anuência. $O$ fórum mencionou que não cabe aos editores solucionar disputas de autoria, razão pela qual seria aconselhado encaminhar o assunto à instituição para investigação, momento em que o editor pode emitir uma nota de preocupação até que o caso seja solucionado (COPE, 2018).

De todo modo, o fórum salientou que, em estudos de caso envolvendo paciente, este tem de autorizar a publicação de artigo em que serve de objeto de estudo e uma saída para tentativa de elucidação da autoria seria, então, o editor buscar o documento em que consta o consentimento do paciente a fim de saber se foi concedido ao pesquisador A ou B (COPE, 2018).

Este caso selecionado, referente ao ano de 2018, envolveu, assim, o incômodo do pesquisador A em não receber os créditos da autoria do trabalho e considerar que a sua contribuição, por ter analisado material cirúrgico do paciente e ter procedido ao diagnóstico, seria suficiente para figurar como autor. 
O fórum do COPE estabeleceu que não cabe ao editor resolver a disputa, mas seria interessante verificar quem foi o responsável pela coleta da autorização do paciente para este ser objeto do artigo (COPE, 2018).

Tanto neste caso, relativo ao ano de 2018, como no anterior, concernente ao exercício de 2016, o fórum orientou que a melhor medida seria buscar a instituição a que os pesquisadores estavam vinculados a fim de fielmente enfrentar o dilema da autoria nos casos concretos (COPE, 2016; COPE, 2018).

Essa é a melhor medida, pois, além de já estudado que a responsabilidade de atribuição da autoria não é do editor, mas, sim, dos próprios autores juntamente com as instituições a que se vinculam, essas, conforme Wager e Kleinert (2014), irão dirimir a questão com base nas especificações da área da Ciência a que o caso está contextualizado, melhor se adequando a cada trabalho científico.

$\mathrm{Na}$ área médica, por exemplo, o pesquisador interessado em produção científica deve estar atento e respeitar as diretrizes formuladas pelo ICMJE, como guia para os autores, de boas práticas para o desenvolvimento, a revisão e a publicação dos trabalhos (SOLARI, 2018).

A pesquisa deve servir como registro não apenas do conteúdo ou do objeto que foi descoberto, mas dos participantes dos resultados obtidos. Os autores devem anuir com a inclusão do seu nome no trabalho científico, bem como devem aprovar a versão a ser publicada. Também, os autores não devem utilizar o espaço dos agradecimentos para indivíduos que não tenham colaborado com o trabalho (WAGER; KLEINERT, 2014).

Como propõe Petroianu (2012), a pontuação de critérios objetivos em torno da fixação da autoria, logo no início do trabalho, por grupos que se propõe a desenvolver um trabalho científico, é meio de prevenir complexos conflitos.

A indicação com coerência, na produção científica, de quem será o autor e de quem figurará como colaborador, com base nas coordenadas traçadas pelos editores e instituições de pesquisa, por sua vez pautadas em diretrizes gerais, como as do CSE, do CNPq, FAPESP, é extremamente importante para garantir a integridade no meio acadêmico, assegurar a ética nas relações e, consequentemente, minimizar as intensas disputas de autorias.

Ressalte-se que, nestes casos, a metodologia do CrediT, conforme analisada na seção anterior, pode auxiliar bastante na identificação de papéis e consequente indicação do pesquisador como autor ou mero colaborador (McNUTT, 2018). 
A aplicação de condutas éticas, em que se inclui a clareza da distinção entre autores e colaboradores, é o que se espera no meio acadêmico. Afinal, leitores de um trabalho científico desejam que tanto os pesquisadores envolvidos na produção quanto os editores sejam confiáveis e honestos. Caso contrário, ocorre não apenas desrespeito aos destinatários da leitura de trabalhos produzidos no meio acadêmico, mas verdadeira corrupção da ciência (MARCOVITCH, 2007).

\section{CONSIDERAÇÕES FINAIS}

As constantes pressões por que passam os pesquisadores, a fim de que aumentem a produtividade e se destaquem no meio acadêmico, vêm ocasionando condutas que comprometem a ética e a integridade dos trabalhos científicos.

Com frequência, ocorrem disputas de autoria envolvendo a ausência de distinção entre quem é o autor e quem deve ficar na posição de mero colaborador da pesquisa desenvolvida. Este artigo apresentou, inclusive, dois casos que foram levados ao COPE, um no ano de 2016 e outro no ano de 2018, em que a ausência de delimitação precisa da autoria ocasionou conflito.

Por meio das diretrizes firmadas pelo CSE, CNPq e FAPESP, além de contribuições bibliográficas sobre a temática, reconhece-se que a autoria, de modo geral, deve ser atribuída a quem contribuiu, substancialmente e com magnitude, desde a primeira etapa da pesquisa até o momento da revisão e publicação do trabalho, cabendo ao autor, portanto, responsabilizar-se pela produção científica.

O próprio COPE estabelece diretrizes em torno da atribuição da autoria, por meio das quais ressalta que o crédito de autor deve ser atribuído ao pesquisador que ofertou substratos relevantes para a realização do trabalho e, por isso, é o responsável pela pesquisa.

Já meras contribuições ofertadas, referente a dados, a planejamentos, a experimentos, que envolvem apenas determinadas etapas da pesquisa ou não demandam esforço intelectual para a aferição do resultado, não são suficientes para conceder aos contribuintes a autoria. Estes devem, então, figurar em uma seção de agradecimento, após expressa autorização, como meros colaboradores. 
É justo aos envolvidos na produção do trabalho e à Academia, como garantia da integridade das produções científicas e do compromisso com a ética, que as contribuições sejam expressamente delimitadas.

O público leitor também espera transparência e integridade não apenas em relação ao conteúdo que aprecia, mas quanto a quem foi o responsável intelectual, de modo substancial, pela pesquisa e quem apenas contribuiu com alguns dados ou ações para que o primeiro investisse e se esforçasse na produção.

É necessário que o meio acadêmico valorize mais a qualidade do que a quantidade da produção. A essência do conhecimento está na grandeza do conteúdo, da inovação, e não na reprodução em massa das mesmas ideias para se alcançar números.

Enquanto essa prática de produção em escala numérica for incentivada, como modo de o pesquisador ganhar prestígio e reconhecimento no meio acadêmico, além de práticas intencionalmente desviadas da ética, existirão os casos em que, por mais cuidadosos que os autores sejam, poderão equivocar-se em relação a suas condutas, como acontece bastante na delimitação das contribuições de autoria e de colaboração.

Em que pese as instituições como o CSE, o CNPq, a FAPESP e o COPE terem desenvolvido disposições éticas acerca das distinções entre as condutas dos participantes de uma pesquisa, a fim de delinear a identificação de quem é o autor e de quem é o colaborador, muitas vezes elas não são investigadas ou seguidas pelos pesquisadores.

Assim, um modo de contribuir para a expansão de conhecimento pelos pesquisadores a fim de que esses, de modo contínuo e responsável, na prática, possam distinguir o autor do colaborador, é o papel dos próprios editores e instituições a que são vinculados, que devem evidenciar, de maneira padronizada, acessível e clara, os papéis de cada contribuidor na pesquisa, com incentivo à assinatura de declaração pelos pesquisadores acerca dos seus papéis, para que haja o menor número de conflitos e se prime pela ética, integridade e honestidade nos trabalhos acadêmicos.

Além disso, acredita-se que tecnologias, como a CrediT, devam ser usualmente manuseadas, pois, reconhecem, delimitam e valorizam as contribuições dos colaboradores. Ainda, se associadas ao Orcid, podem registrar o papel de cada pesquisador do trabalho, dirimindo eventuais dúvidas em torno da autoria.

\section{REFERÊNCIAS}


ASSOCIAÇÃO BRASILEIRA DE EDITORES CIENTÍFICOS (ABEC). Diretrizes do CSE para promover integridade em publicações de periódicos científicos: atualização de 2012 . São Paulo: ABEC $2017 . \quad$ Disponível em: https://www.abecbrasil.org.br/arquivos/whitepaper_CSE.pdf. Acesso em: 25 jun. 2019.

BEDÊ, Fayga Silveira; SOUSA, Raphaella Prado Aragão de. Metáforas sobre o tempo e estilização da escrita acadêmica: tempo de criação ou de produção? Um diálogo com a literatura. Revista Internacional de Direito e Literatura. Anamorphosis, v. 4, n. 2, p. 525542, jun/dez. 2018.

BEDÊ, Fayga Silveira; MESQUITA, Érica Linhares; PUCCI, Fernanda Patrícia Lima de Oiveira. Receita fast food para o autoplágio em Direito: duas doses de ensino jurídico homogeneizante e uma de produtivismo acadêmico - bata tudo até obter uma massa uniforme de pesquisadores-copistas - sirva com moderação. Revista Eletrônica do Curso de Direito da UFSM. Universidade Federal de Santa Maria, v. 13, n. 3, p. 1205-1231, 2018.

COMMITTEE ON PUBLICATION ETHICS - COPE. How to handle authorship disputes: a guide for new researchers. 2003. Disponível em: https://publicationethics.org/files/2003pdf12_0.pdf. Acesso em: 21 jun. 2019.

COMMITTEE ON PUBLICATION ETHICS - COPE. Disclosure and transparency. 2016. Disponível em: https://publicationethics.org/case/disclosure-and-transparency-issue. Acesso em: 21 jun. 2019.

COMMITTEE ON PUBLICATION ETHICS - COPE. Authorship conflict. 2018. Disponível em: https://publicationethics.org/case/authorship-conflict. Acesso em: 21 de junho de 2019.

COMMITTEE ON PUBLICATION ETHICS - COPE. About COPE. 2019. Disponível em: https://publicationethics.org/about/our-organisation. Acesso em: 21 jun. 2019.

CONSELHO NACIONAL DE DESENVOLVIMENTO CIENTÍFICO E TECNOLÓGICO CNPq. A Comissão de Integridade na Atividade Científica - CIAC. 2019a. Disponível em: http://www.cnpq.br/web/guest/apresentacao-comissao-de-integridade. Acesso em: 17 jun. 2019.

CONSELHO NACIONAL DE DESENVOLVIMENTO CIENTÍFICO E TECNOLÓGICO CNPq. Relatório da Comissão de Integridade de Pesquisa do CNPq. 2019b. Disponível em: http://www.cnpq.br/documents/10157/a8927840-2b8f-43b9-8962-5a2ccfa74dda/. Acesso em: 18 jun. 2019.

DOMINGUES, Eliane. Autoria em andamentos de "produtivismo acadêmico". Psicol estud. Maringá, v. 18, n. 2, p. 195-198, junho de 2013. Disponível em: http://www.scielo.br/scielo.php?script=sci_arttext\&pid=S1413-

$73722013000200001 \& \operatorname{lng}=$ en\&nrm=iso. Acesso $\quad$ em: $17 \quad$ ago. 2019 . http://dx.doi.org/10.1590/S1413-73722013000200001. 
FUNDAÇÃO DE AMPARO À PESQUISA DO ESTADO DE SÃO PAULO - FAPESP. Código de Boas Práticas Científicas. São Paulo: FAPESP, 2014. Disponível em: http://www.fapesp.br/boaspraticas/FAPESP-Codigo_de_Boas_Praticas_Cientificas_2014.pdf. Acesso em: 18 jun. 2019.

GARCIA, Carla Costa. et al. Autoria em artigos científicos: os novos desafios. Revista Brasileira de Cirurgia Cardiovascular, São José do Rio Preto, v. 25, n. 4, p. 559567 , Dec. 2010.

http://www.scielo.br/scielo.php?script=sci_arttext\&pid=S0102-

$76382010000400021 \& \operatorname{lng}=\mathrm{en} \& \mathrm{nrm}=$ iso.

Acesso em: 17 ago. 2019. http://dx.doi.org/10.1590/S0102-76382010000400021.

MARCOVITCH, Harvey. Má conduta por pesquisadores e autores. Gac Sanit, Barcelona, $\begin{array}{llll}\text { v. } 21, & \text { p. } 6, & \text { 492-499, } & \text { dez. 2007. Disponível }\end{array}$ http://scielo.isciii.es/scielo.php?script=sci_arttext\&pid=S0213-

91112007000600011\&lng=en\&nrm=iso. Acesso em: 17 ago. 2019.

McNUTT, Marcia Kemper. et al. Transparency in authors' contributions and responsibilities to promote integrity in scientific publication. PNAS. v. 115, n. 11, p. 2557-2560, fev. 2018.

MONTEIRO, Rosangela. et al. Critérios de autoria em trabalhos científicos: um assunto polêmico e delicado. Revista Brasileira de Cirurgia Cardiovascular, São José do Rio Preto, v. 19, n. 4, p. III-VIII, Dec. 2004. Disponível em: http://www.scielo.br/scielo.php?script=sci_arttext\&pid=S0102-

$76382004000400002 \& \operatorname{lng}=$ en\&nrm=iso.

Acesso

em: 17 ago. 2019. http://dx.doi.org/10.1590/S0102-76382004000400002.

PETROIANU, ANDY. Autoria de um trabalho científico. Revista da Associação Médica Brasileira, São Paulo, v. 48, n. 1, p. 60-65, mar. 2002. Disponível em http://www.scielo.br/scielo.php?script=sci_arttext\&pid=S0104-

42302002000100034\&lng=en\&nrm=iso. Acesso $\quad$ em: $\quad 17$ ago. 2019. http://dx.doi.org/10.1590/S0104-42302002000100034.

PETROIANU, Andy. Distribuição da autoria em trabalhos científicos. ABCD, arq. bras. cir. escavação. São Paulo, v. 25, n. 1, p. 60-64, mar. 2012. Disponível em: http://www.scielo.br/scielo.php?script=sci_arttext\&pid=S0102-

67202012000100014\&lng=en\&nrm=iso. Acesso em: 14 ago. 2019. http://dx.doi.org/10.1590/S0102-67202012000100014.

SOLARI, Lely. Boas práticas e princípios éticos: mais necessários do que nunca. Rev. gastroenterol. Peru, Lima, v. 38, n. 3, p. 306-309, jul. 2018. Disponível em: http://www.scielo.org.pe/scielo.php?script=sci_arttext\&pid=S1022-

51292018000300015\&lng=en\&nrm=iso. Acesso em: 17 ago. 2019.

TARGINO, Maria das Graças. Orientador, tutor o director de tesis, ¿es autor? Informação \& Informação, Londrina, v. 15, n. esp, p. 145-156, 2010. Disponível em: http://www.uel.br/revistas/uel/index.php/informacao/article/view/7623. Acesso em: 17 ago. 2019. doi:http://dx.doi.org/10.5433/1981-8920.2010v15n1espp145. 
VANZ, Samile Andrea de Souza; STUMPF, Ida Regina Chittó. Colaboração científica: revisão teórico-conceitual. Perspect. ciênc. inf., Belo Horizonte , v. 15, n. 2, p. 4255, Ago. 2010 Acesso em: http://www.scielo.br/scielo.php?script=sci_arttext\&pid=S141399362010000200004\&ng=en\& nrm=iso.

Disponível em: 14 ago. 2019. http://dx.doi.org/10.1590/S141399362010000200004.

VILAÇA, Murilo Mariano. Más condutas científicas uma abordagem crítica comparativa para formar uma reflexão sobre o tema. Revista Brasileira de Educação, Rio de Janeiro, v. 20, n. 60, p. 245-269, mar. 2015. Disponível em: http://www.scielo.br/scielo.php?script=sci_arttext\&pid=S141324782015000100245\&lng=en\&nrm=iso. Acesso $\quad$ em: $17 \quad$ ago. 2019 . http://dx.doi.org/10.1590/S1413-24782015206012.

WAGER, Elizabeth; KLEINERT, Sabine. Publicação responsável de pesquisa: padrões internacionais para autores. Caderno de Pesquisa, São Paulo , v. 44, n. 151, p. 219226, Mar. 2014. Disponível em: http://www.scielo.br/scielo.php?script=sci_arttext\&pid=S0100-

$15742014000100012 \& \operatorname{lng}=$ en\&nrm=iso.

Accesso em: 17 ago. 2019. http://dx.doi.org/10.1590/198053142845. 